\title{
TREATMENT OF PERTHES' DISEASE OF THE HIP BY CANCELLOUS BONE GRAFTING
}

\section{Preliminary Report}

\author{
A. J. M. Cathro and W. H. Kirkaldy-Willis, Nairobi, Kenya \\ From the Orthopaedic Centre, Nairobi
}

It is generally conceded that the conservative treatment of Perthes' disease of the hip is unsatisfactory. In a recent study of the late results of conservative treatment in fifty-two cases followed up for ten or more years, Evans (1958) showed that one-third developed good femoral heads, one-third fair heads and one-third poor heads, as judged radiologically. Howorth (1948) pointed out that there is a considerable individual variation in all the features of the disease, especially in the radiographic appearances. Not only does this fact make the evaluation of treatment difficult, it makes prognosis impossible. Confronted with an early case the surgeon cannot tell whether the end-result will be a deformed head or a well shaped head, no matter what treatment is given. The findings of Evans and Lloyd-Roberts (1958) suggested that present practice has little effect on the course of the disease. These authors compared the late results of in-patient and out-patient methods of treatment. The in-patients were treated by rest in bed and immobilisation of the hip, and the out-patients with a Snyder sling and crutches. They found no significant difference in the final radiographic appearances in the two groups. Prolonged conservative treatment would be acceptable if it could be shown to be really effective, but, as these reviews indicate, this is not the case. Any method that would hasten regeneration of the femoral head without detriment to the final result would therefore be a real advance.

Perhaps some of the poor results of conservative treatment are due to failure to prevent weight bearing for long enough. Brailsford (1953), with a prolonged experience of 115 cases, considered that the period of plasticity of the femoral head lasts from three months to four years from the onset of the disease. Howorth (1948) stated that Perthes' disease runs a characteristic course of four to seven years. The logical conclusion is that the young patient must not be allowed to bear weight on the hip for at least four years. In the past, patients and surgeons alike have baulked at this bleak prospect. For example, the average period of nonweight bearing in Evans and Lloyd-Roberts's cases was only two years and one month. Before criticising conservative treatment too severely therefore, we should remember that very few patients are treated for what appears to be the optimum time.

\section{RATIONALE OF OPERATIVE TREATMENT}

Whatever the ultimate cause, it is commonly thought that in Perthes' disease the bony epiphysis of the head of the femur dies from lack of blood supply. The concept that Perthes' disease is a result of a vascular accident is in keeping with the finding that no method of conservative treatment makes any difference to the result, provided weight bearing is avoided. The individual variations in the course of the disease could also be explained on this basis, presumably depending on variations in the development of a collateral circulation and in the recanalisation of vessels previously obliterated. Once the disease sets in there is no known method of preventing sequestrum formation. Nevertheless it seems reasonable to aid the growth of new vessels into the femoral head by drilling across the epiphysial plate, which is a barrier to the development of collateral circulation from the metaphysis. The assumption is that the vascular irruption so produced will speed up both the removal and the regeneration of bone in the head. 
Howorth (loc. cit.) reviewed fifty cases treated in this way and concluded that degeneration of the head of the femur and residual deformity were reduced and that the period of convalescence was shortened by about a third. Nevertheless, he felt that this period was still too long.

The next logical step is to remove the dead bone of the head and to pack the remaining cavity with cancellous bone chips. This should promote osteogenesis more certainly than drilling and should be superior to the peg grafts of cortical bone which have sometimes been used.

Cancellous chip grafting of the femoral head has been employed in this Centre in ten cases of Perthes' disease in an attempt to evolve a better method of treatment than we have at present.

\section{THE OPERATION}

The hip is exposed through a Smith-Petersen approach. The capsule is incised parallel to the long axis of the femoral neck so as to interfere with the blood supply of the femoral head as little as possible. A window is cut in the anterior aspect of the neck close to the head. Through this opening the dead bone of the head is curetted out with a sharp spoon or small gouge. The less the fragmentation of the head as seen radiologically, the more difficult it is to remove the bone completely. In early cases the bone is dense and hard. It is not always possible to remove all the dead bone, but radiographic control during operation is useful to show how much has actually been achieved in this respect. Complete removal is not absolutely necessary. Follow-up has shown that when some dead bone has been left behind re-ossification occurs just as rapidly as in those in which all sequestra have been removed.

In most cases the cartilage of the femoral head is intact, and except in late cases it preserves its original shape, although radiographs may show flattening of the bony head. The preservation of the normal shape of the cartilaginous head has also been shown by arthrography and is a further argument in favour of using cancellous bone chips which can be packed tightly to fill the whole cavity in the head, rather than cortical peg grafts which can occupy only part of it. The cancellous bone chips are taken from the healthy bone of the neck removed in cutting the approach to the head, and from the adjacent iliac crest.

After operation the affected limb is immobilised by Pugh's extension for three to six months depending on the rate of regeneration of the femoral head. Thereafter the patient is allowed up with a Snyder sling, but weight bearing is not permitted until radiographs show almost complete regeneration of the bony trabeculae of the head. In this series the period of non-weight bearing after operation averaged seven months.

\section{RESULTS}

In assessing the results of this method of treatment only two factors have been considered: the time taken for complete regeneration of the femoral head, and the ultimate shape of the head as measured by the epiphysial index (Eyre-Brook 1936).

Rate of regeneration of the head as judged radiographically-The time table of the sequence of events in Perthes' disease drawn up by Brailsford has been used as a standard for estimating the age of the lesion. For convenience it is summarised here (Table I). The average time for complete re-ossification of the femoral head after operation was fifteen months (Table II). This compares with Evans's average of twenty-five months. The shortest time for regeneration after operation was approximately five months and the longest twenty-four months.

It will be noted that although the average period of non-weight bearing after operation was only seven months, the average time for regeneration of the femoral head was fifteen months. This simply indicates that whereas the initial regeneration of the head was rapid, final consolidation was much slower. We agree with Herndon and Heyman (1952) that once regeneration of the head is well established further collapse is unlikely to occur even if weight bearing is allowed. In evaluating the operation this short period of non-weight bearing should be taken into account.

VOL. 45 B, NO. 2, MAY 1963 
There appeared to be no relationship between the rate of regeneration of the head and the stage of the disease at which the operation was done. For example, in one patient operated on eighteen months after the onset of the disease the femoral head took twenty-three months

TABLE I

Evolution of Perthes' Disease (after Brailsford)

\begin{tabular}{|c|c|c|}
\hline Radiographic appearance & Age of lesion & State of bone \\
\hline \multicolumn{3}{|l|}{ Increased density } \\
\hline Increased joint space & $2-3$ months & Becoming plastic \\
\hline \multicolumn{3}{|l|}{ Osteoporosis of diaphysis } \\
\hline \multicolumn{3}{|l|}{ Fracture, flattening, "fragmentation" } \\
\hline Absorption of fragments & $3-18$ months & Plastic \\
\hline \multicolumn{3}{|l|}{ Expansion of diaphysis } \\
\hline \multicolumn{3}{|l|}{$\begin{array}{l}\text { Early regeneration plus absorption of } \\
\text { dense fragments }\end{array}$} \\
\hline Absorption of last dense nucleus & $1 \frac{1}{2}-4$ years & Plastic \\
\hline \multicolumn{3}{|l|}{ Recalcification of diaphysis } \\
\hline Normal bone in epiphysis & 4 years onwards & Solid \\
\hline
\end{tabular}

TABLE II

Clinical Details of Ten Patients Treated for Perthes' Disease by Cancellous Bone Grafting

\begin{tabular}{|c|c|c|c|c|c|c|c|c|c|}
\hline \multirow{3}{*}{$\begin{array}{c}\text { Case } \\
\text { number }\end{array}$} & \multirow{3}{*}{ Age } & \multirow{3}{*}{ Sex } & \multirow{3}{*}{$\begin{array}{l}\text { Estimated } \\
\text { time of } \\
\text { diagnosis } \\
\text { after onset } \\
\text { (months) }\end{array}$} & \multirow{3}{*}{$\begin{array}{l}\text { Estimated } \\
\text { time of } \\
\text { operation } \\
\text { after onset } \\
\text { (months) }\end{array}$} & \multirow{3}{*}{$\begin{array}{l}\text { Time for } \\
\text { regeneration } \\
\text { after } \\
\text { operation } \\
\text { (months) }\end{array}$} & \multicolumn{4}{|c|}{ Epiphysial index } \\
\hline & & & & & & \multicolumn{2}{|c|}{ Normal side } & \multicolumn{2}{|c|}{ Affected side } \\
\hline & & & & & & $\begin{array}{c}\text { Before } \\
\text { treatment }\end{array}$ & $\underset{\text { treatment }}{\text { After }}$ & $\begin{array}{c}\text { Before } \\
\text { operation }\end{array}$ & $\begin{array}{c}\text { After } \\
\text { operation }\end{array}$ \\
\hline 1 & 3 & $\mathbf{F}$ & 12 & 14 & 5 & 28 & 27 & 23 & 22 \\
\hline 2 & 4 & $\mathbf{M}$ & 7 & 10 & 12 & 46 & 50 & 14 & 20 \\
\hline 3 & 4 & $\mathbf{M}$ & 7 & 13 & 24 & 46 & 43 & 17 & 20 \\
\hline 4 & 5 & F & 6 & 6 & 8 & 50 & 50 & 33 & 27 \\
\hline 5 & 5 & F & 3 & 5 & 14 & 40 & 37 & 30 & 23 \\
\hline 6 & 6 & $\mathbf{M}$ & 4 & 18 & 23 & 55 & 50 & 21 & 30 \\
\hline 7 & 6 & $\mathbf{M}$ & 4 & 9 & 24 & 50 & 43 & 23 & 25 \\
\hline 8 & 7 & $F$ & 10 & 14 & 6 & 40 & 35 & 12 & 10 \\
\hline 9 & 7 & $\mathrm{~F}$ & 6 & 12 & 16 & 44 & 37 & 33 & 20 \\
\hline 10 & 8 & $\mathbf{M}$ & 4 & 4 & 22 & 45 & 46 & 33 & 12 \\
\hline
\end{tabular}

to re-ossify completely, whereas another head grafted only five months after the onset took almost as long to regenerate. In the patient with the most rapid re-ossification of the femoral head there was a delay of fourteen months before intervention. 


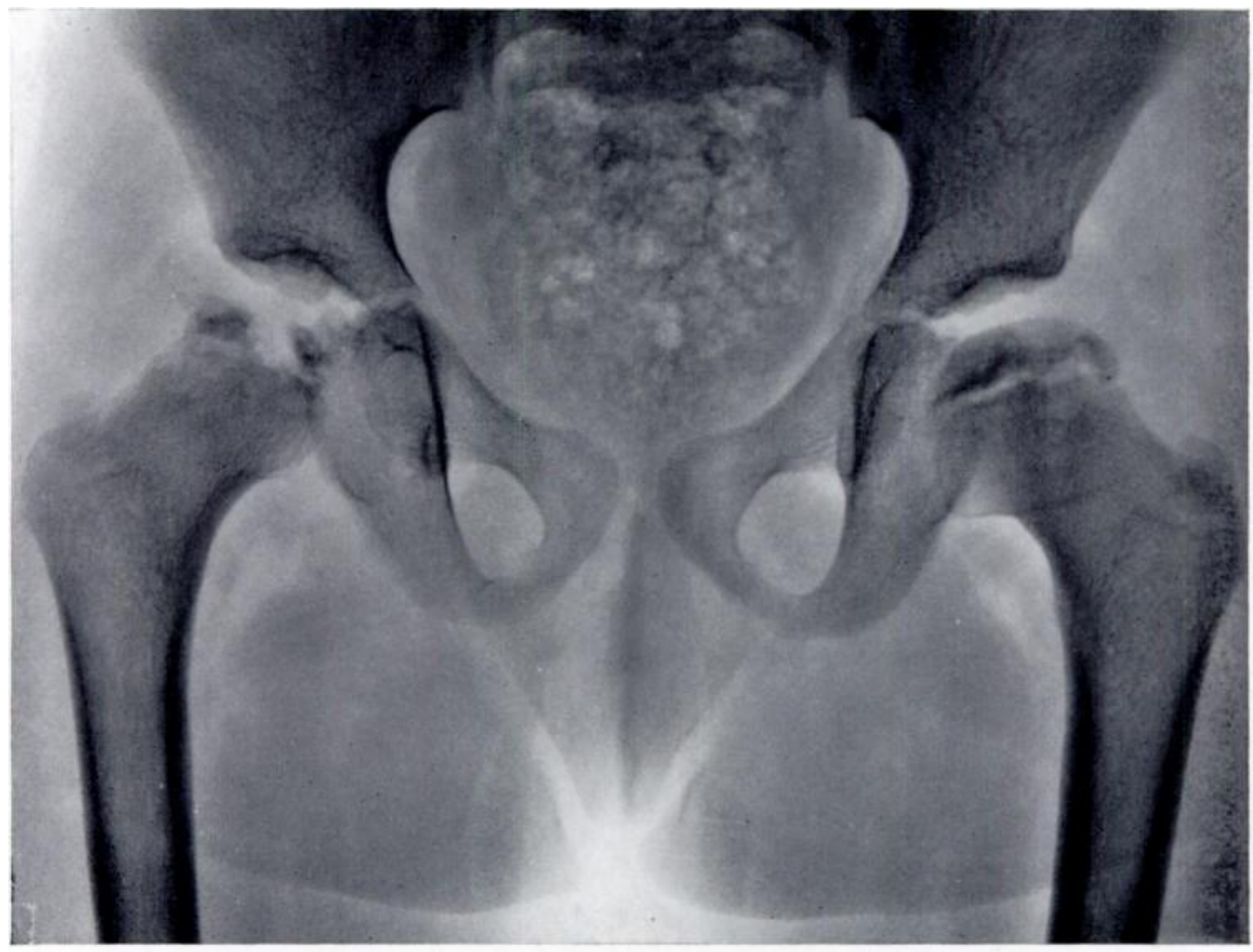

Fig. 1

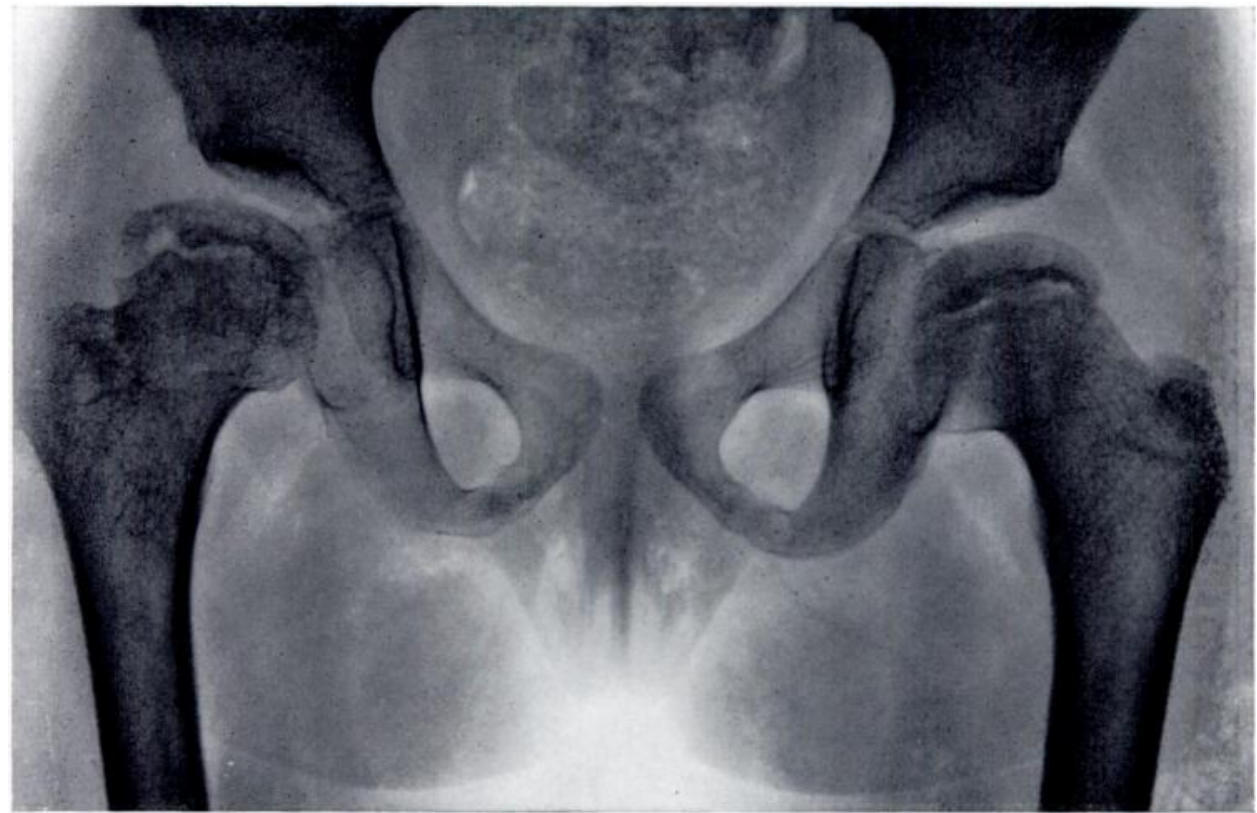

Fig. 2

Case 1. Figure 1-Before operation. Figure 2-Five months after operation. Rapid regeneration of head. Note changes of early Perthes' disease on "normal " side. 


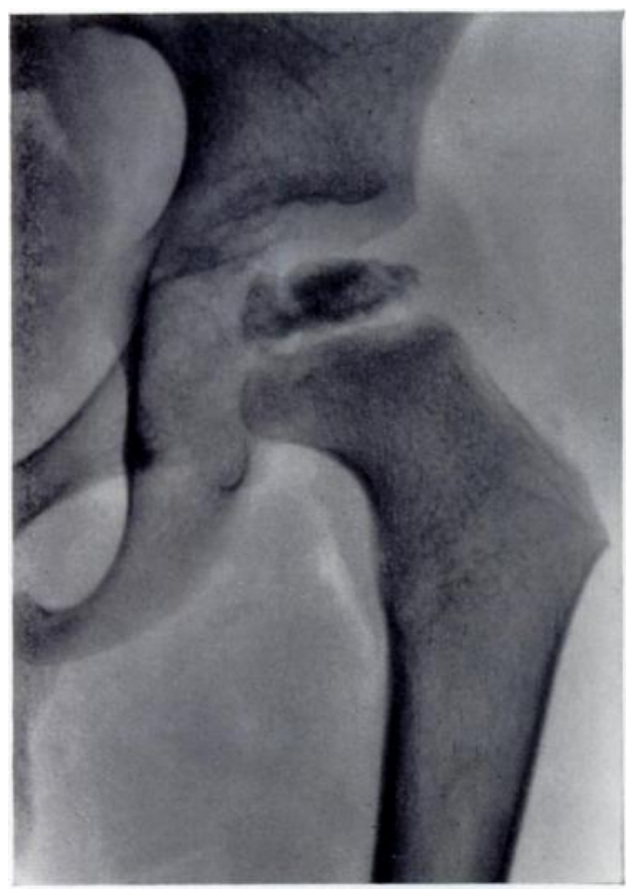

FIG. 3

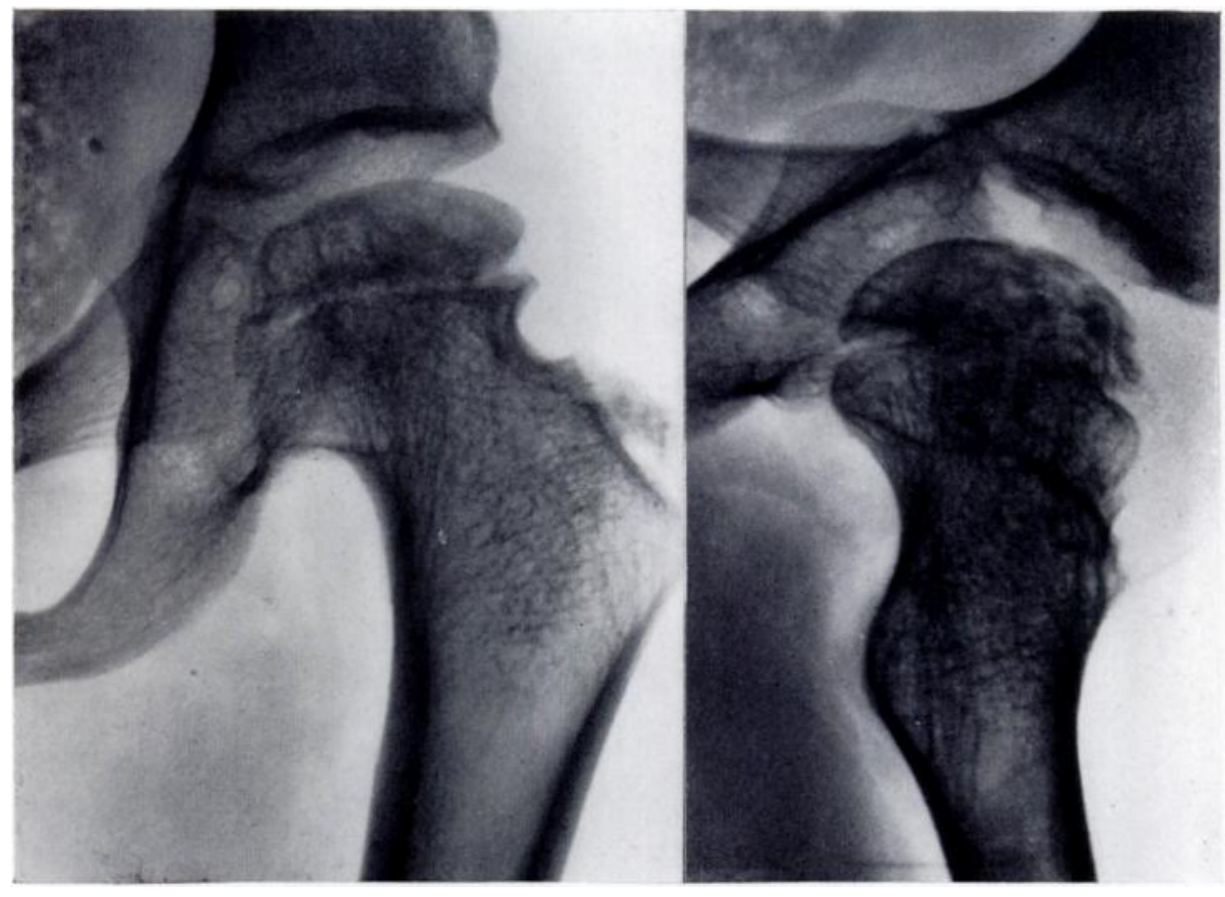

Fig. 5

Case 6-Showing greatest improvement in shape of head in the whole series. Figure 3-Before operation. Figure 4-Six months after operation. Figure 5-Eighteen months after operation. 
Regarding the speed of regeneration of the head and its ultimate shape, twenty-three months were required for full regeneration in the patient in whom the epiphysial index improved most. On the other hand, in the patient with the greatest deterioration of the epiphysial index regeneration took nearly as long as this, and when regeneration was most rapid (five months) there was no improvement at all in the shape of the head. In other words no obvious relationship could be made out between the rate of re-ossification of the femoral head and its final shape. The epiphysial index (capital index) - The epiphysial index is the ratio of the height of the capital epiphysis to its depth. It is determined as follows:

$$
\frac{\text { Height of epiphysis }}{\text { Breadth of epiphysis }} \times 100 \text {. }
$$

It is therefore an indication of the shape of the femoral head. The lower the epiphysial index the flatter the head. The normal value varies with age and is said to be 35 to 45 over seven

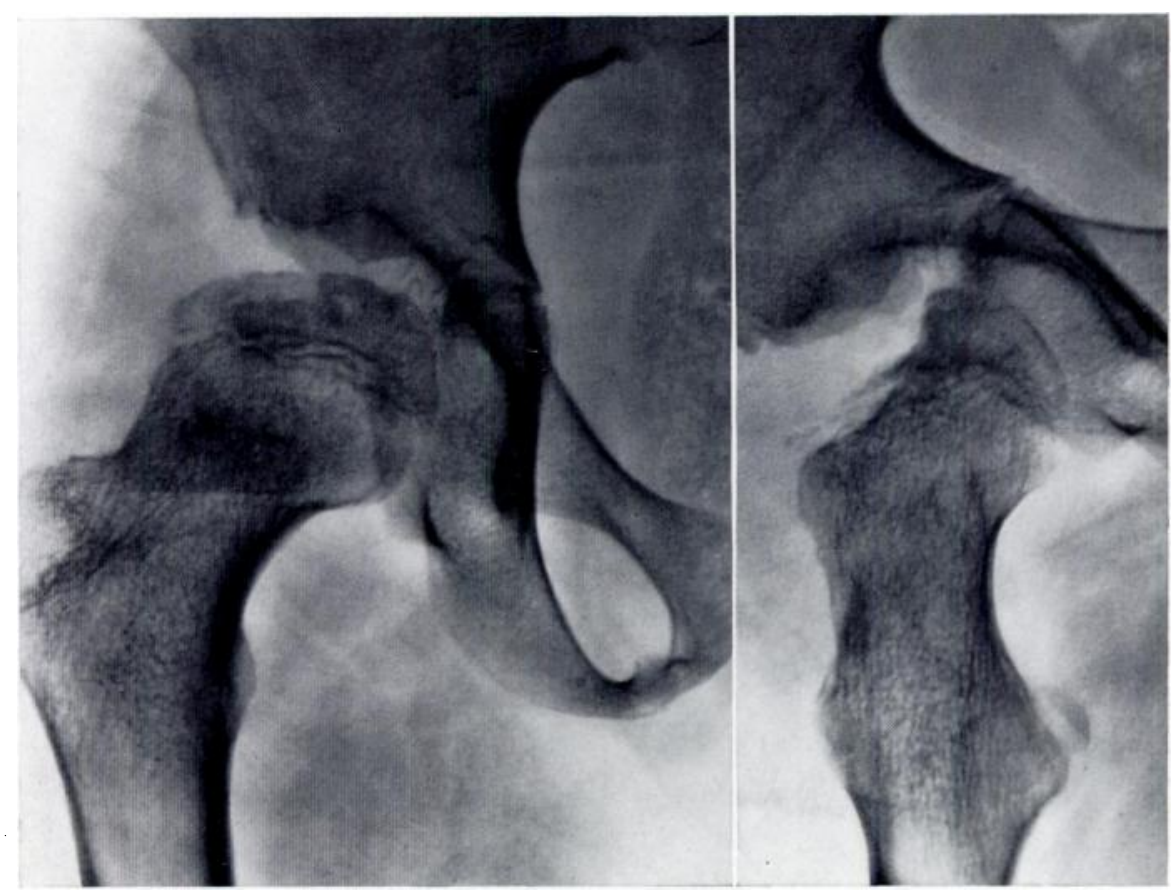

Fig. 6

Antero-posterior and lateral radiographs of the same hip to show the fallacies inherent in one view only.

years and 45 to 55 under this age. It should be realised however that a low epiphysial index does not necessarily mean a bad result. The index takes no account of the shape of the head in relation to the depth of the acetabulum or to the shape of the neck. When these factors are considered many cases with a low capital index can be shown to be much more normal than the shape of the head would suggest (Heyman and Herndon 1950). Nevertheless as a standard for comparison, both with normally shaped femoral heads and with other cases of Perthes' disease, the epiphysial index is a quick and satisfactory means of representing the results of treatment. In this series of patients treated by cancellous chip grafting none of the femoral heads was normal to begin with. The epiphysial index varied from 12 to 33 in those over seven years old and from 14 to 33 under this age. By the time of final consolidation after operation, the epiphysial index "improved"-that is, the shape of the femoral head approximated more to normal-in four cases (Figs. 3-5) and deteriorated in six (Table II).

vol. 45 B, NO. 2, MAY 1963 
In half the cases, however, these changes in shape for better or for worse were so slight as to be negligible. When the shape of the heads before operation is taken into account these results are little different from those of conservative treatment.

With regard to the time of operation after the onset of the disease and the ultimate shape of the head, the best result was obtained when the operation was delayed longest, the worst result in the case operated on soonest. But the number of cases is so small that this finding cannot be taken as an indication of when to operate.

\section{DISCUSSION}

In a disease in which some authorities think that no treatment does any good (Platt 1921, Sundt 1921, Legg 1927) and in which the proponents of conservative treatment claim only one-third good results (Evans 1958) it is obvious that the evaluation of any method of treatment is difficult, especially when only a few cases are available for study. This is only a preliminary report, and clearly if there is merit in the method described it must be substantiated by a longer follow-up of many more cases.

In considering the epiphysial index and the final result we should note that all the femoral heads were grossly flattened before operation, the index varying from 33 down to 12 . This is an indication of the late stage at which these patients were first seen. It is possible that operation would be more beneficial earlier in the disease, although this did not seem to be the case here. A glance at Table II shows no relationship between the shape of the head at the time of operation and the result. This is contrary to Eyre-Brook's (1936) finding that the earlier in the disease that treatment was begun the better the result. Whereas Howorth (1948) thought that the drilling operation reduced the residual deformity there was no evidence that cancellous chip grafting did so.

Also relevant to the operative results is the state of the femoral head on the normal side during treatment. In two cases the epiphysial index increased, in seven it decreased (the normal trend as time goes on) and in one it remained unchanged. This rise in the epiphysial index with increasing age suggests either that these heads were not normal or that during normal growth there are fluctuations in shape and that growth does not proceed evenly to the adult pattern. An investigation of a large series of children without hip pathology is needed for a correct interpretation of the changes in Perthes' disease.

Case 1 (Table II) is particularly interesting. Here the "normal" head at the time of diagnosis of Perthes' disease on the opposite side showed very early changes of osteochondritis with an epiphysial index of only 28 (normal range at this age 45-55). This head recovered its trabecular pattern without undergoing much increase in density and without any fragmentation, but the epiphysial index remained low (Figs. 1 and 2). Clearly it is important to know whether such a hip will develop osteoarthritis in later life. Because of these changes in the normal hips, in discussing the results in terms of the final shape of the femoral head we did not think it worth while to compare the diseased and the normal sides.

Fate of the epiphysial plate-A criticism that might be levelled against the operation is that it destroys the epiphysial plate. Apart from the fact that this region is responsible only for growth in length of the femoral neck and not for growth in length of the shaft proper, which takes place at the lower end of the bone, for some reason the epiphysial line after being partly obliterated reappears after the operation.

The expression epiphysial "line" is misleading. The epiphysial line is a radiological, not an anatomical entity. The epiphysial plate of cartilage is not a line but a disc, and to appreciate fully any changes occurring in it and in the adjacent head lateral radiographs are essential (Fig. 6). Careful examination of the serial radiographs in the cases treated by grafting shows that part of the periphery of the epiphysial disc is usually left behind. It is most likely that the epiphysial plate regenerates from these peripheral cartilage cells, which seemingly are able to prevent the process of ossification within the bone grafts at the site of the old epiphysial plate. 


\section{SUMMARY AND CONCLUSIONS}

1. Cancellous bone grafting of the head of the femur in Perthes' disease accelerates reossification and thus shortens the period of treatment.

2. There is no evidence from this series of cases that the final shape of the head is affected for better or for worse by the operation of cancellous chip grafting, by the rate of regeneration of the head after operation or by the stage in the disease process at which the operation is done. 3. No relationship has been found between the shape of the head at the time of operation and its final shape.

4. A larger series of cases is needed to determine the value of bone grafting in Perthes' disease of the hip.

\section{REFERENCES}

Brailsford, J. F. (1953): The Radiology of Bones and Joints. Fifth edition. London: J. \& A. Churchill Ltd. Evans, D. L. (1958): Legg-Calvé-Perthes' Disease. Journal of Bone and Joint Surgery, 40-B, 168.

Evans, D. L., and Lloyd-RoberTs, G. C. (1958): Treatment in Legg-Calvé-Perthes' Disease. Journal of Bone and Joint Surgery, 40-B, 182.

Eyre-Brook, A. L. (1936): Osteochondritis Deformans Coxae Juvenilis or Perthes' Disease. British Journal of Surgery, 24, 166.

Herndon, C. H., and Heyman, C. H. (1952): Legg-Perthes Disease. Journal of Bone and Joint Surgery, 34-A, 25. Heyman, C. H., and Herndon, C. H. (1950): Legg-Perthes Disease. Journal of Bone and Joint Surgery, 32-A, 767. Howorth, M. B. (1948): Coxa Plana. Journal of Bone and Joint Surgery, 30-A, 601.

LEGG, A. T. (1927): The End Results of Coxa Plana. Journal of Bone and Joint Surgery, 9, 26.

Platt, H. (1921): Pseudo-coxalgia. British Journal of Surgery, 9, 366.

Sundt, H. (1921): Quiet Hip Disease in Childhood. Medical Review, 24, 29. 